\title{
Simplified nonlinear analysis of reinforced concrete coupling beams subjected to cyclic loading
}

Rafael Alves de Souza (Main and Corresponding Author)

Civil Engineering Department, State University of Maringá

Avenida Colombo, 5790, Jardim Universitário, 87020-900. Maringá (Brazil)

rsouza@uem.br

https://orcid.org/0000-0002-9990-2850

\section{Sergio F. Breña}

Department of Civil and Environmental Engineering, University of Massachusetts Amherst

Natural Resources Road, 130. Amherst (United States of America)

brena@umass.edu

https://orcid.org/0000-0002-7159-7401

Manuscript Code: 13666

Date of Acceptance/Reception: 19.11.2020/16.01.2020

DOI: 10.7764/RDLC.19.3.224

\begin{abstract}
Reinforced concrete shear walls connected by coupling beams form an efficient structural system to resist earthquake and wind loads in tall buildings. However, the analysis of the effects caused by cyclic loading in this kind of system are not so straightforward. In the present paper, simplified nonlinear analysis using monotonic loading are used in order to obtain the behavior of tested coupling beams subjected to cyclic loading. Numerical results have shown that numerical monotonic loading is able to predict with good precision the yielding and the failure loads of the tested coupling beams subjected to cyclic loading. Both the cracking patterns and the predicted failure modes were captured reasonably well in comparison with the experimental behavior. Therefore, monotonic simulations may be applied to have a first estimate of the envelope curve for cyclic loading.
\end{abstract}

Keywords: reinforced concrete, coupling beams, non-linear analysis, cyclic loading.

Introduction

The primary purpose of beams between coupled walls during earthquake actions is the transfer of shear from one wall to the other. Coupling beams have, typically, short span-to-depth ratios and are consequently governed by shear failure. However, in this specific scenario, the behavior of coupling beams is significantly affected by shear reversals and large cyclic inelastic deformations, as observed by Jang \& Hong (2004). If the brittle failure of the coupling beams is prevented, a large fraction of the input seismic energy is dissipated, and consequently, building performance is improved.

While numerical investigation of conventional reinforced concrete beam-column joints subjected to lateral loading is profoundly studied the same cannot be said for short coupling beams connecting walls. For conventional reinforced concrete connections whose behavior is dominated by flexural mechanisms, there are a number of FEM software that can perform such an analysis with reasonable accuracy, as shown in Mahini \& Ronagh (2011) and Masi et al. (2013).

In contrast, reinforced concrete elements whose behavior is dominated by shear mechanisms, as the case of coupling beam between walls, the accuracy of software is of great concern, especially when cyclic loading is applied. The simulation of these discontinuity regions is a very complicated numerical problem and many papers have discussed these difficulties and challenges, as for example, Haris \& Roszevák (2019), Najafgholipour et al. (2017) and Hawileh et al. $(2010,2012)$.

According to the Prestandard for Seismic Simulation of Buildings (ASCE, 2000), the nonlinear response of elements may be estimated in a simplified manner through the use of force-deformation envelopes. These envelopes are intended to capture the essential features of the nonlinear response of structural components for use primarily in nonlinear static analysis of structures.

It is worth to observe that using monotonic curves to represent the cyclic response of structural components has some important limitations. The effects of number of load cycles, for example, is neglected. Also, the effects of loading history and previous damage are not captured. These deficiencies can be partially overcome by constructing monotonic curves 
of force-deformation response obtained from envelopes of elements tested experimentally under cyclic loading, thereby capturing the mechanisms described above.

The present paper proposes the utilization of simplified monotonic analysis for approaching the yielding loads and failure loads of a group of coupling beams tested under cyclic loading conditions. It is shown that simple monotonic analysis can be used as a first approach for predicting the complex behavior of structures subjected to cyclic loading with reasonable accuracy.

\section{Experimental Results}

\section{Materials and methods}

Four coupling beam specimens were tested by one of the authors (Breña \& Ihtiyar, 2011) with the primary intent to investigate effects of reinforcing characteristics on failure mode. Specimens were designed using a concrete mix with a nominal compressive strength of $30 \mathrm{MPa}$. Nominal yield strength of the longitudinal and transverse reinforcement was $410 \mathrm{MPa}$, except for specimen CB-2 that had transverse reinforcement consisting of deformed wire with a nominal yield strength of $580 \mathrm{MPa}$. Figure 1 illustrates the geometry and reinforcement patterns, while Table 1 presents the measured properties of the materials used in the four specimens.

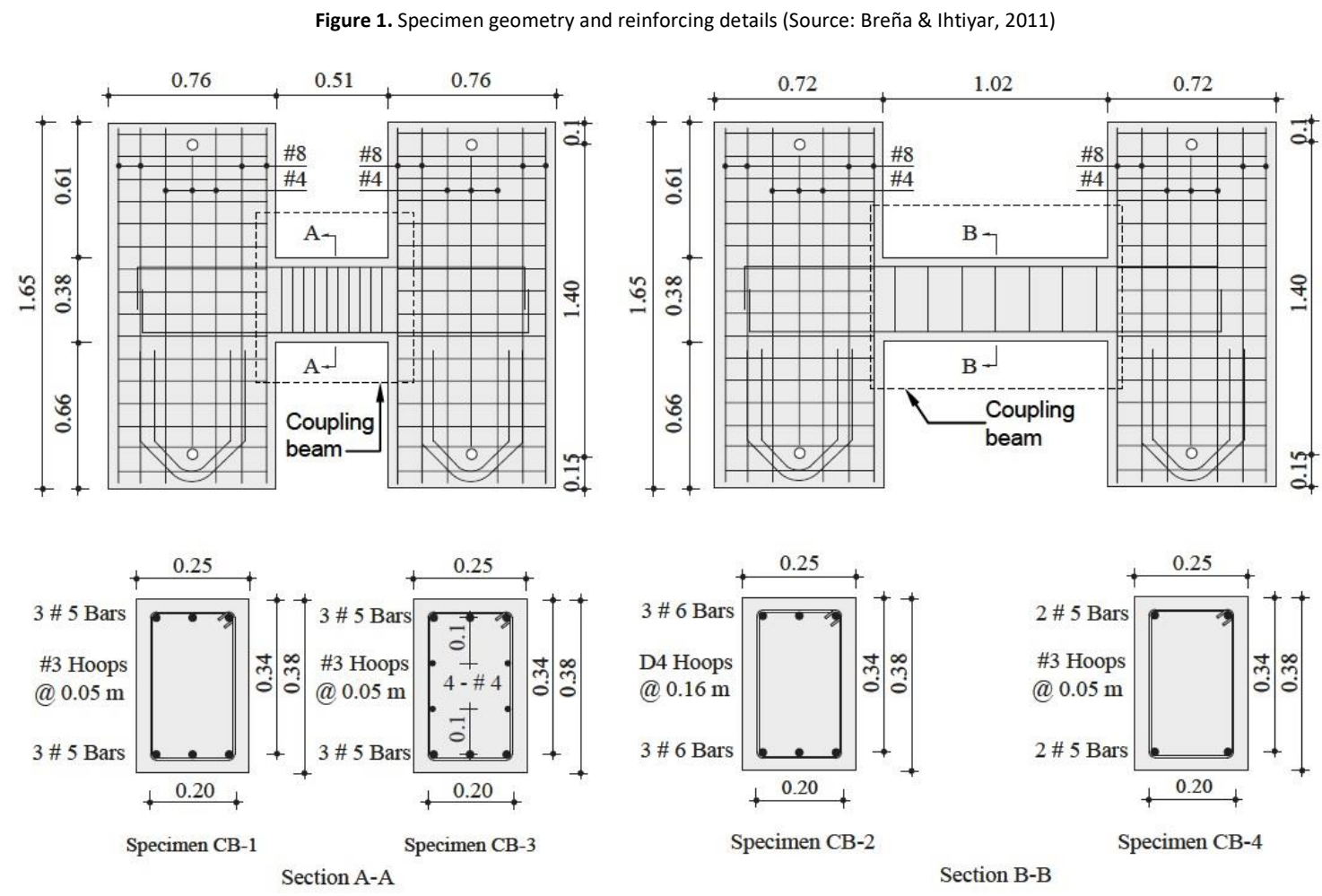

Table 1. Measured material properties according to Breña \& Ihtiyar (2011)

\begin{tabular}{|c|c|c|c|c|c|c|c|}
\hline \multirow[b]{2}{*}{ Specimen } & \multirow{2}{*}{$\begin{array}{c}\text { Depth } \\
\mathrm{d} \\
(\mathrm{mm})\end{array}$} & \multirow{2}{*}{$\begin{array}{c}\text { Span } \\
I_{n} \\
(\mathrm{~mm})\end{array}$} & \multicolumn{2}{|c|}{$\begin{array}{c}\text { Longitudinal } \\
\text { Reinforcement }\end{array}$} & \multicolumn{2}{|c|}{$\begin{array}{c}\text { Transverse } \\
\text { Reinforcement }\end{array}$} & \multirow{2}{*}{$\begin{array}{c}\text { Concrete } \\
\text { Strength } \\
\mathrm{f}_{\mathrm{c}} \\
(\mathrm{MPa})\end{array}$} \\
\hline & & & $A_{s l}$ & $\begin{array}{c}\mathrm{f}_{\mathrm{yl}} \\
(\mathrm{MPa})\end{array}$ & $A_{s t}$ & $\begin{array}{c}\mathrm{f}_{\mathrm{yt}} \\
(\mathrm{MPa})\end{array}$ & \\
\hline CB-1 & 340 & 510 & $\begin{array}{c}\text { 3\#5 (16 } \\
\mathrm{mm})\end{array}$ & 517 & $\begin{array}{c}\# 3(9 \mathrm{~mm}) \\
\text { each } 50 \mathrm{~mm}\end{array}$ & 524 & 39 \\
\hline CB-2 & 340 & 1020 & $\begin{array}{c}\text { 3\#6 (19 } \\
\mathrm{mm})\end{array}$ & 448 & $\begin{array}{c}\mathrm{D} 4(6 \mathrm{~mm}) \\
\text { each } 160 \\
\mathrm{~mm}\end{array}$ & 607 & 39 \\
\hline CB-3 & 270 & 510 & $\begin{array}{c}3 \# 5 \text { (16 } \\
\mathrm{mm}) \\
2 \# 4(13 \\
\mathrm{mm})\end{array}$ & $\begin{array}{l}517 \\
469\end{array}$ & $\begin{array}{c}\# 3(9 \mathrm{~mm}) \\
\text { each } 50 \mathrm{~mm}\end{array}$ & 524 & 31 \\
\hline CB-4 & 340 & 1020 & $\begin{array}{c}3 \# 5(16 \\
\mathrm{mm})\end{array}$ & 517 & $\begin{array}{c}\# 3(9 \mathrm{~mm}) \\
\text { each } 50 \mathrm{~mm}\end{array}$ & 524 & 30 \\
\hline
\end{tabular}


In the experimental setup, forces were generated in the coupling beams by applying horizontal forces to two stiff concrete walls constructed on each end of the specimens, as shown in Figure 2. Horizontal loading was distributed to the top of the walls using a stiff steel element that imposed equal lateral displacement to both walls, generating in that way, shear $(\mathrm{V})$ and flexure $(\mathrm{M})$ in the coupling beams.

Figure 2. Test setup for the walls (Source: Breña \& Ihtiyar, 2011)

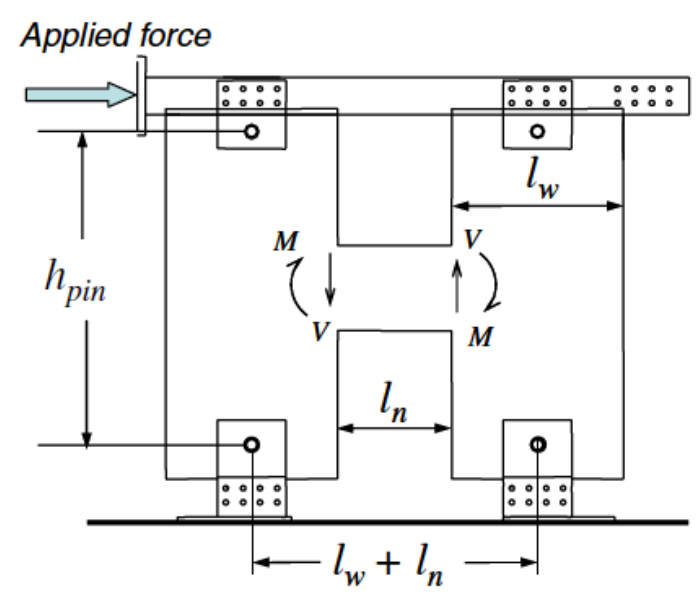

Lateral force was applied cyclically in sets of three cycles at pre-defined amplitude. Applied loading was force-controlled in pre-yield stages and subsequently changed to displacement control at post-yield stages. At loading stages below the estimated yield shear force $\left(V_{y}\right)$, the applied loading amplitudes were $1 / 3,2 / 3$, and $3 / 3$ of $V_{y}$. The lateral displacement at the top of the walls at $V_{y}$ was defined as the displacement at yield. Subsequent loading was applied in increments of 0.5 times the yield displacement. Loading was stopped as specimens began to lose strength at higher applied displacements since the primary intent was to determine the stiffness of the loading branch and the factors contributing to coupling beam deformation.

The cyclic shear force-chord rotation behavior of the four beams tested in the experimental program are shown in Figure 3, from which several response features could be highlighted. Specimens CB-1 and CB-3 (short shear span) exhibited essentially similar cyclic characteristics. Both specimens reached approximately the same shear force and were able to develop similar chord rotations at yield and peak shear force. The influence of horizontal web reinforcement in CB-3 did not affect the general characteristics of the hysteretic response significantly, but did increase the measured chord rotation at yield.

Figure 3. Cyclic shear force-chord rotation response of the tested coupling beams. (Source: Breña \& Ihtiyar, 2011)
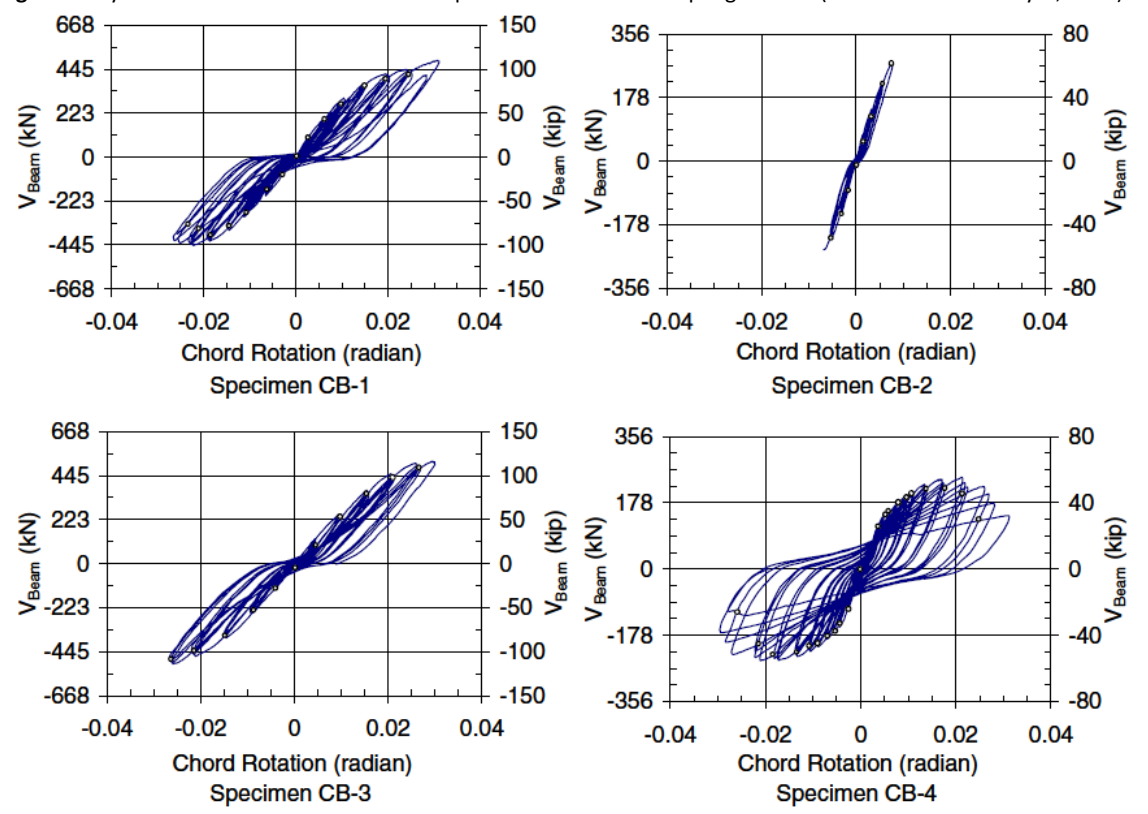
The highly contrasting behavior of specimens CB-2 and CB-4 (slender shear span), although with the same span to-depth ratio, was primarily caused by the significantly different amounts of transverse reinforcement. Transverse reinforcement in CB-2 was barely sufficient to maintain shear strength after formation of the first diagonal crack and resulted in a brittle failure mode with no yielding of the longitudinal reinforcement.

On the other hand, $C B-4$ had a very ductile response as a result of low flexural strength $\left(\mathrm{V}_{\mathrm{f}}\right)$ and relatively high shear capacity $\left(V_{n}\right)$. Specimen $C B-4$ was the only beam that had a higher shear strength than required to develop plastic hinging and spread of plasticity near beam ends. Also, only specimen CB-4 was taken to much higher displacements because it was designed to be flexurally dominated and its shear retention capacity at large displacements (residual strength) was of particular interest.

According to Breña \& Ihtiyar (2011), unlike Specimens CB-1 and CB-3, which exhibited extensive cracking throughout their span, cracking in Specimens CB-2 and CB-4 was concentrated primarily near the beam ends. Observed cracking in these specimens was similar to that observed in the hinging regions of slender beams, although diagonal cracks almost joined near midspan at higher displacement amplitudes in Specimen CB-2, and remained concentrated near the beam ends in Specimen CB-4.

\section{Nonlinear Analysis Using ATENA2D}

Results and discussion

According to Cervenka \& Cervenka (1996), nonlinear finite element analysis of reinforced concrete structures has been under steady development in recent decades. The commercial computer programs featuring nonlinear material models are offered and codes of practice are reflecting this progress. Commercially available codes allow for the analysis of entire structures or structural members with very realistic material behavior, and a simulation of structural performance under real loading conditions is possible nowadays.

In order to better investigate the coupling beams tested by Breña \& Ihtiyar (2011), the package software ATENA2D was selected as it presents powerful constitutive models for structural concrete. Besides that, previous experiences of the authors (Souza et al., 2007; Souza \& Breña, 2016) with the constitutive model SBETA shows that nonlinear finite element simulations can be used not only for the analysis of ultimate loads, but also for the analysis of the service conditions for crack widths, crack spacing and deflections.

Figure 4 shows an example of the finite element mesh and the boundary conditions adopted for the tested specimens, where the stress fields generated by the horizontal load can be seen. The finite element mesh was modelled using macroelements and discretized using CClsoQuad type elements. Horizontal loads were applied at the top of the walls and pinned supports were defined at the bottom of the walls in order to simulate the experimental setup.

Figure 4. Stress fields for the tested coupling beam connecting walls (a) compression fields and (b) tension fields
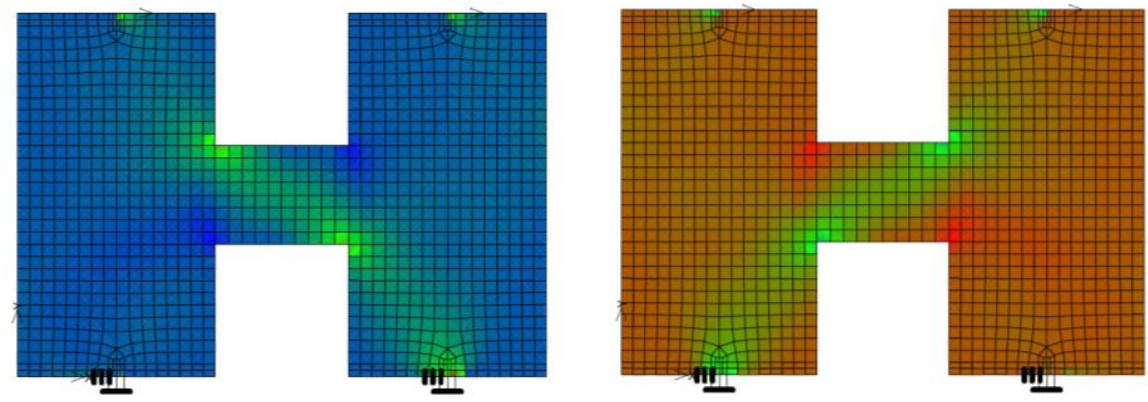

The longitudinal and transverse reinforcing bars were modeled with their actual geometry, and with the strength properties of the concrete and reinforcing bars based on the laboratory tests presented in Table 1. Only the compressive strength and the tensile strength of the concrete were defined, while the other values were automatically defined by the software based on the Ceb-Fip Model Code 1990 (1993).

Several models and solvers have been tested using monotonic loading, in order to check the level of approximation of this simplified approach for cyclic loading. The best results were obtained using the SBETA model combined with the fixed crack model, perfect bond, smeared reinforcement (bilinear model with hardening) and iteration method based on the Newton-Raphson approach. 
According to Cervenka \& Cervenka $(2003,2005)$ all the important features of the concrete behavior are covered in the selected SBETA constitutive model, as for example: non-linear behavior in compression including hardening and softening; fracture of concrete in tension based on the nonlinear fracture mechanics; biaxial strength failure criterion; reduction of compressive strength after cracking; tension stiffening effect and reduction of the shear stiffness after cracking (variable shear retention)

The first cracks for the Specimen CB-1 occurred at the corners of the coupling beam for a total horizontal force of 57,2 $\mathrm{kN}$ or a shear force in the coupling beam of $62,92 \mathrm{kN}$. First yielding was computed in the top main reinforcement (16 $\mathrm{mm}$ bars with yielding strength of $517 \mathrm{MPa}$ ) at the same position where the first cracks were registered. The main reinforcement yielded at a total horizontal force of $361,40 \mathrm{kN}$ corresponding to a shear force in the coupling beam of $397,54 \mathrm{kN}$.

The cracking behavior was firstly characterized by the degradation of the interface between the walls and the coupling beam. The first diagonal cracks appeared at a total horizontal force of $170,48 \mathrm{kN}$ corresponding to a shear force in the coupling beam of $187,55 \mathrm{kN}$. After this, the number of diagonal cracks increased throughout the span, with the crack widths at the interface between beam and walls being more significant.

Figure 5 shows the estimated cracking pattern for Specimen CB-1 at peak load compared with the experimentally observed cracking pattern at that same load level. The calculated peak load occurred for a total horizontal force of $384,20 \mathrm{kN}$ at a shear force in the coupling beam of 422,62 kN. Figure 5 also shows the cracking regions for the concrete and crack widths just above $0,2 \mathrm{~mm}$.

Immediately after the peak load was registered for Specimen CB-1, a suddenly jump in stresses estimated in the two last stirrups ( $9 \mathrm{~mm}$ reinforcement bars with yielding strength of $524 \mathrm{MPa}$ ) situated at the right side of the beam was observed. These two stirrups started to yield at a total horizontal force of $366 \mathrm{kN}$ corresponding to a shear force in the coupling beam of $402,60 \mathrm{kN}$. A drop in strength ensued for the subsequent load steps.

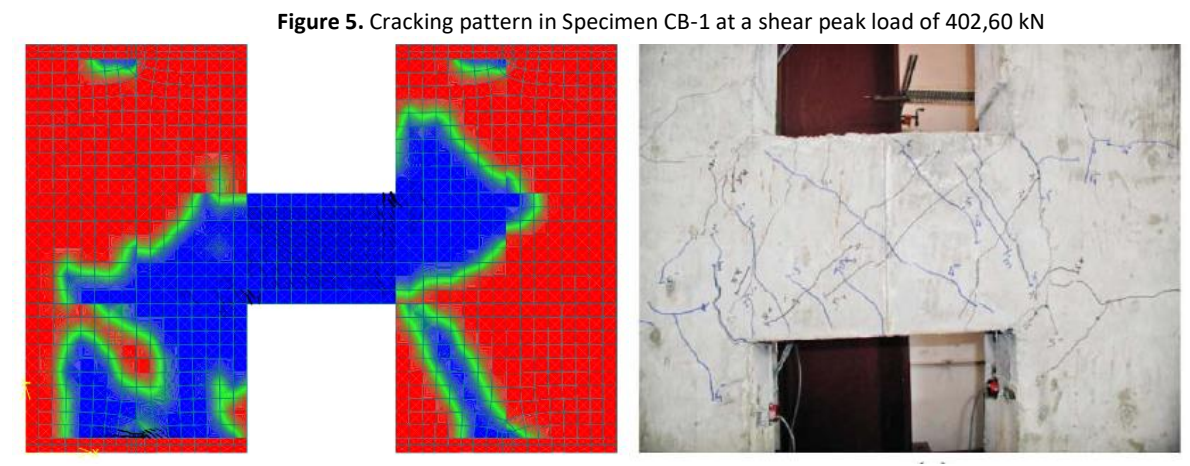

The first cracks for Specimen CB-2 developed at the corners of the coupling beam at a total horizontal force of 39,74 kN or a shear force in the coupling beam of $31,79 \mathrm{kN}$. First yielding occurred in the critical stirrup at a total horizontal force of $289,40 \mathrm{kN}$ or a shear force in the coupling beam of $231,52 \mathrm{kN}$. Yielding was registered in the third stirrup from left to right in the coupling beam at a stress of $606 \mathrm{MPa}$.

Figure 6 shows the estimated cracking pattern of Specimen CB-2 at peak load and a comparison with the observed cracking pattern during the laboratory tests at failure. The numerical peak load was estimated at a total horizontal force of $292,40 \mathrm{kN}$ or a shear force in the coupling beam of 233,92 kN. Figure 6 also shows the cracking regions for the concrete and crack widths just above $0,2 \mathrm{~mm}$. The stress for the main reinforcement at the peak load was about $389 \mathrm{MPa}$.

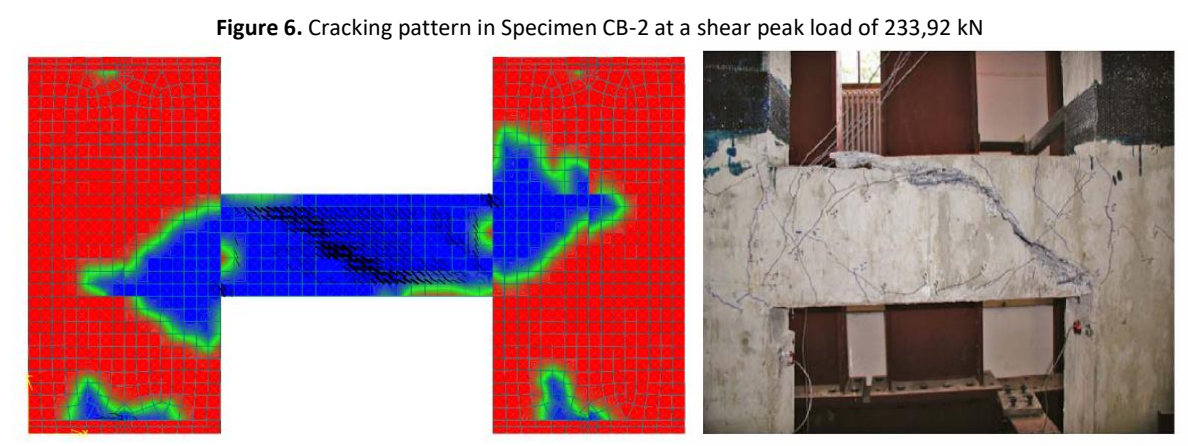


The cracking behavior was firstly characterized by the degradation of the interface between the walls and the coupling beam. The first diagonal cracks appeared at a total horizontal force of 157,16 kN or a shear force in the coupling beam equal to $125,72 \mathrm{kN}$. Subsequently, additional diagonal cracks formed throughout the span and started to widen until the peak load was reached. At failure the critical diagonal crack widened and cracking distribution was widespread throughout the span.

The first cracks in Specimen CB-3 were estimated to form at the corners of the coupling beam at a total horizontal force of $39,84 \mathrm{kN}$ or a shear force in the coupling beam of $43,82 \mathrm{kN}$. Additionally, first yielding occured at the same load in stirrups (third stirrup from the left to right) and the main top longitudinal reinforcement at a total horizontal force of $380,60 \mathrm{kN}$ or a shear force in the coupling beam of $418,66 \mathrm{kN}$. Top reinforcing bars (16 mm bars) had a yield strength of $517 \mathrm{MPa}$, while stirrups ( $9 \mathrm{~mm}$ reinforcing bars) had yield strength of $524 \mathrm{MPa}$.

Figure 7 shows the cracking pattern for Specimen CB-3 at peak load. The calculated peak load occurred at a total horizontal force of $380,60 \mathrm{kN}$ or a shear force in the coupling beam of 418,66 kN. Figure 7 also shows the cracking regions for the concrete and estimated crack widths of approximately $0,2 \mathrm{~mm}$. The cracking behavior was initially characterized by the degradation of the interface between the walls and the coupling beam. The first diagonal cracks appeared at a total horizontal force of $140,56 \mathrm{kN}$ corresponding to a shear force in the coupling beam of 154,61 kN. Additional diagonal cracks formed after this load and were distributed broadly throughout the span. Existing cracks widened until reaching the peak load. At failure, the crack widths in the interface between beam and walls had increased notably.

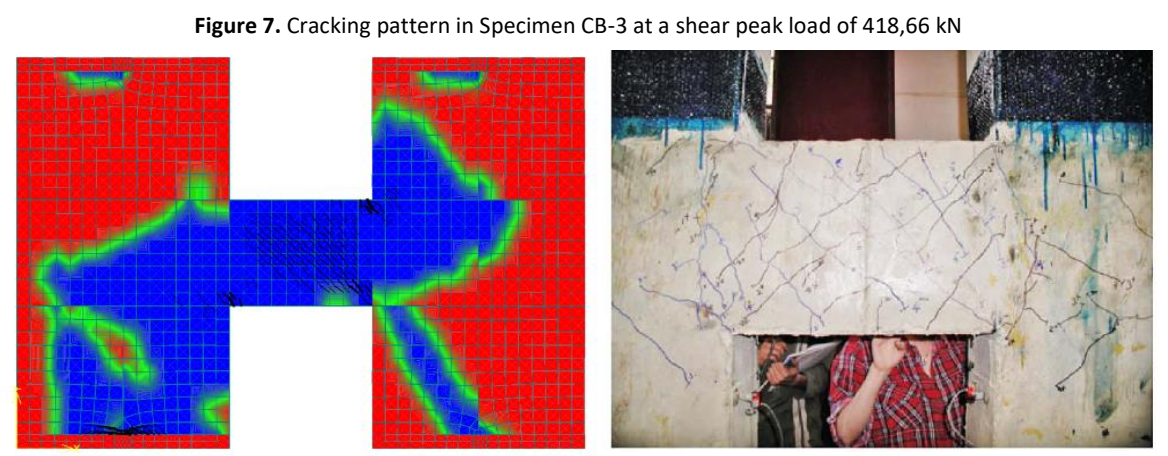

The first cracks for Specimen CB-4 formed at the corners of the coupling beam at a total horizontal force of $38 \mathrm{kN}$ or a corresponding shear force in the coupling beam of 30,40 kN. First yielding in the main top reinforcement occurred at a total horizontal force of $195,46 \mathrm{kN}$ or a shear force in the coupling beam of 156,36 kN. Top reinforcing bars (16 mm bars) have a yield strength of $517 \mathrm{MPa}$.

Figure 8 shows the calculated and observed cracking patterns for Specimen CB-3 at peak load. The calculated peak load occurred at a total horizontal force of $281,40 \mathrm{kN}$ or a shear force in the coupling beam of 225,12 kN. Figure 8 shows the cracked regions in the concrete and with maximum crack widths just above $0,2 \mathrm{~mm}$. No yielding was computed in stirrups in the models constructed using ATENA2D.

The cracking sequence was first characterized by degradation of the interface between the walls and the coupling beam. The initial diagonal cracks appeared at a total horizontal force of $162,04 \mathrm{kN}$, associated with a shear force in the coupling beam of $129,63 \mathrm{kN}$. Subsequently, diagonal cracks formed and were distributed throughout the span while the cracks that had previously formed at the interface between the beam and wall continued widening until reaching peak load. At failure, shear sliding occurred at the critical crack that formed along the beam-wall interface.

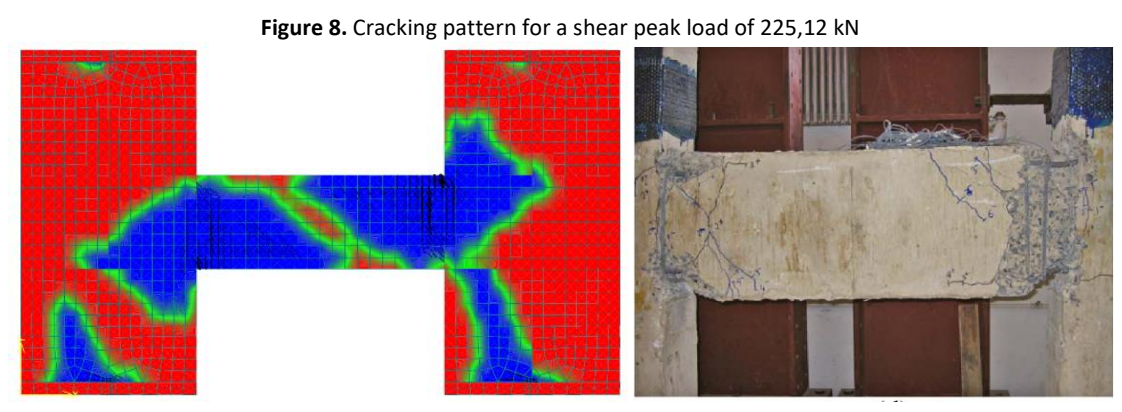


After conducting the nonlinear analysis using ATENA2D and constructing the monotonic loading curve for the models representing tested specimens, it is possible to observe that the numerical simulations were able to capture with reasonable precision the cracking behavior as well as the yielding and failure loads, as shown in Table 2.

Table 2. Calculated results using ATENA2D

\begin{tabular}{|c|c|c|c|c|}
\hline Specimen & $\begin{array}{l}\mathrm{V}_{\mathrm{yl}} \\
(\mathrm{kN})\end{array}$ & $\begin{array}{l}\mathrm{V}_{\mathrm{yt}} \\
(\mathrm{kN})\end{array}$ & $\begin{array}{l}V_{\text {peak }} \\
(\mathrm{kN})\end{array}$ & Failure mode captured in simulations \\
\hline CB-1 & 397,54 & 402,60 & 422,62 & $\begin{array}{l}\text { Yielding of the longitudinal reinforcement followed by } \\
\text { the yielding of the stirrups }\end{array}$ \\
\hline CB-2 & - & 231,52 & 233,92 & Yielding of the transverse reinforcement \\
\hline CB-3 & 418,66 & 418,66 & 418,66 & $\begin{array}{l}\text { Yielding of the longitudinal reinforcement and } \\
\text { transverse reinforcement at the same time }\end{array}$ \\
\hline CB-4 & 156,36 & - & 225,12 & $\begin{array}{l}\text { Yielding of the longitudinal reinforcement followed by } \\
\text { the rupture of the longitudinal reinforcement }\end{array}$ \\
\hline
\end{tabular}

Where $\mathrm{V}_{\mathrm{yl}}$ = shear load causing yielding of the longitudinal steel; $\mathrm{V}_{\mathrm{yt}}=$ shear load causing yielding of the transverse steel and $\mathrm{V}_{\text {peak }}=$ shear at peak load.

Table 3 compares the calculated numerical results with the measured experimental results. Experimental values were taken from the cyclic-force envelopes measured during the tests, while the numerical results were obtained using monotonic loading. As one can see, good predictions for yielding and loads at failure were obtained using numerical monotonic loading. The mean measured to calculated force at general yield was 0,98 and the corresponding ratio at peak was 1,11 . The coefficients of variations were $5,15 \%$ and $6,26 \%$, respectively. Although the sample size is small, the results lend confidence to the ability of the numerical models to capture key values in the measured response accurately.

Table 3. Comparison between experimental and numerical results using ATENA2D

\begin{tabular}{|c|c|c|c|c|c|c|}
\hline \multirow[b]{2}{*}{ Specimen } & \multicolumn{3}{|c|}{ Yielding Loads } & \multicolumn{3}{|c|}{ Peak Loads } \\
\hline & $\begin{array}{l}V_{y, \exp } \\
(k N)\end{array}$ & $\begin{array}{c}V_{y, \text { num }} \\
(\mathrm{kN})\end{array}$ & $\begin{array}{l}V_{y, \exp } / \\
V_{y, \text { num }}\end{array}$ & $\begin{array}{c}V_{\text {peak,exp }} \\
(\mathrm{kN})\end{array}$ & $\begin{array}{c}\text { Veak,num } \\
(\mathrm{kN})\end{array}$ & $\begin{array}{l}V_{\text {peak,exp }} / \\
V_{\text {peak,num }}\end{array}$ \\
\hline CB-1 & 414 & 397.54 & 1.04 & 478 & 422.62 & 1.13 \\
\hline CB-2 & 226 & 231.52 & 0.97 & 275 & 259.84 & 1.05 \\
\hline CB-3 & 409 & 418.66 & 0.97 & 506 & 418.66 & 1.20 \\
\hline \multirow[t]{4}{*}{ CB-4 } & 142 & 156.36 & 0.90 & 240 & 225.12 & 1.06 \\
\hline & & Mean & 0.97 & & Mean & 1.11 \\
\hline & & SD & 0.05 & & SD & 0.06 \\
\hline & & COV & $5.15 \%$ & & COV & $6.28 \%$ \\
\hline
\end{tabular}

While the yielding and the failure loads were quite good, the same cannot be said for the displacements. The concrete degradation due to cyclic loads cannot be included in the proposed simplified analysis and, as consequence, the predicted deformations are lower than the experimental results.

Even using more complex nonlinear analyses based on cyclic constitutive laws for the reinforcement (Menegotto-Pinto and Bauschinger effect) and simulations mimicking the loading protocol used during the tests, the hysteresis behavior observed in the experimental investigation was very difficult to be reproduced. The obtained results were very timeconsuming to obtain and were not able to represent well the observed experimental behavior, indicating the high complexity of the problem regarding displacements.

The behavior of the selected coupling beams was previously simulated numerically by Breña et al. $(2009,2010)$ using the package software jConc (Ruiz \& Muttoni, 2007) and despite the good results regarding the ultimate load, the mentioned software was also not able to adequately considerer the degradation of the concrete due to the cyclic loading. Stiffness degradation of concrete subjected to cyclic loading, particularly during large displacement amplitudes, plays a significant role in the shear force - chord rotation relationship of coupling beams. Besides that, length to depth ratio, reinforcement layout, amount of transverse reinforcement and failure mode (bending or shear) have a significant influence on the strength and behavior (deformation capacity) of the coupling beams.

Although a crude approximation, one way to better represent the stiffness reduction that occurs during cyclic inelastic deformations when using a simplified monotonic approach is to reduce the modulus of elasticity of the concrete ( $\left.E_{c}\right)$. According to Paulay (1971), Park \& Ang (1985) and Ihtiyar \& Breña (2007), degradation in the modulus of elasticity due 
to cyclic loading plays a significant role in the deformational behavior and estimates of $E_{c} / 4$ is an initial estimate to better estimate the displacements are not uncommon.

Furthermore, for the case of coupling beams that are typically shear dominated components, it is also important to consider reductions in the shear modulus $\left(\mathrm{G}_{c}\right)$. These reductions can result in values in the order of $0.15 \mathrm{G}_{c}$ to capture the measured deformations accurately.

\section{Conclusions}

Coupling beams connecting structural walls at floor levels is a common and efficient structural system used for lateralload resistance in medium-rise buildings. In buildings within seismic regions, the load retention and displacement capacity of coupling beams are paramount for the success of the system. Brittle shear failures may occur in coupling beams, and for that reason more advanced tools need to be applied in order to predict the behavior of coupling beams.

In the present paper, nonlinear analysis techniques using ATENA2D coupled with simple monotonic loading was used to ably predict, with reasonable precision the yielding and failure loads of laboratory tested coupling beams. Target loads were accurately predicted for all members, regardless of beam aspect ratio (length/depth), reinforcement layout and failure mode. The cracking patterns and also the predicted failure modes followed the experimental behavior indicating that the proposed approach can be used to predict strength of coupling beams subjected to cyclic loads in a simple way.

In contrast, the obtained numerical displacements were much lower than the obtained experimental results. The reasons for this difference are obviously in the monotonic loading and in the lack of monotonic loading to capture strength and stiffness degradation that occurs with cyclic loading. Once the experimental models were submitted to loading and unloading cycles, the shear degradation in the experiments is much more significant than that one obtained using a simple monotonic loading.

The concrete degradation produced by cyclic loading results in loss in stiffness resulting in increased displacement compared with displacements obtained using simple monotonic loading. A simple way to better estimate the displacements is to define a lower modulus of elasticity for the concrete. While this approach is not definitive and accurate, it is undoubtedly a very fast procedure to estimate strength and deformation of coupling beams subjected to complex cyclic loading.

References

ASCE (2000) Prestandard and Commentary for the Seismic Rehabilitation of Buildings. FEMA 356 Report, American Society of Civil Engineers for the Federal Emergency Management Agency, Washington DC.

Breña, S., Ruiz, M.F., Kostic, N., \& Muttoni, A. (2009). Modelling techniques to capture the backbone envelope behavior of coupling beams subjected to seismic loading. Studies and researches, vol 29, graduate school in concrete structures - Fratelli Pesenti, Politechnico di Milano, Italy. https://ibeton.epfl.ch/Pubs/2009/Brena09.pdf

Breña, S. F., Ruiz, M. F., \& Muttoni, A. (2010). Applications of stress fields to assess the behavior and strength of coupling beams subjected to seismic actions. In: 3rd fib International Congress, Washington D.C., USA. https://infoscience.epfl.ch/record/163108

Breña, S., \& Ihtiyar, O. (2011). Performance of conventionally reinforced coupling beams subjected to cyclic loading. Journal of Structural Engineering, 137(6). https://doi.org/10.1061/(ASCE)ST.1943-541X.0000316

Cervenka, V., \& Cervenka, J. (1996). Computer simulation as a design tool for concrete structures. In: The Second International Conference in Civil Engineering on Computer Applications, ICCE-96, Research and Practice, 6-8 April, Bahrain. https://core.ac.uk/download/pdf/147553393.pdf

Cervenka, V., \& Cervenka, J. (2003). ATENA Program documentation - part 2-1: User's manual for ATENA2D”, Prague. https://www.cervenka.cz/products/atena/documentation/

Cervenka, V., \& Cervenka, J. (2005) ATENA Program documentation - part 2-2: User's manual for ATENA3D, Prague. https://www.cervenka.cz/products/atena/documentation/

Comité Euro-International du Béton. 1993. CEB-FIP Model Code 1990. Thomas Telford Services, Ltd., London.

Haris, I., \& Roszevák, Z. (2019). Finite element analysis of cast-in-situ rc frame corner joints under quasi-static and cyclic loading. Revista de la Construcción, 18 (3), 579-594. http://dx.doi.org/10.7764/rdlc.18.3.579

Jang, S. K., \& Hong, S. G. (2004). The shear strength of rc coupling beams with plastic hinges using strut-and-tie model. In: 13th World Conference on Earthquake Engineering, Vancouver, Canada. https://www.iitk.ac.in/nicee/wcee/article/13_1480.pdf 
Hawileh, R.A., Rahman, A., \& Tabatabai, H. (2010). Nonlinear finite element analysis and modeling of a precast hybrid beam-column connection subjected to cyclic loads. Applied Mathematical Modelling, 34 (9), 2562-2583. https://doi.org/10.1016/j.apm.2009.11.020

Hawileh, R.A., Abdalla, J.A., \& Tanarslan, M.H. (2012). Modeling of nonlinear response of r/c shear deficient t-beam subjected to cyclic loading. Computers and Concrete, 10 (4), 413-428. http://dx.doi.org/10.12989/cac.2012.10.4.419

Mahini, S.S., \& Ronagh, H.R. (2011). Web-bonded frps for relocation of plastic hinges away from the column face in exterior rc joints. Composite Structures, 93(10), 2460-2472. https://doi.org/10.1016/j.compstruct.2011.04.002

Masi, A., Santarsiero, G., Lignola, G.P., \& Verderame, G.M. (2013). Study of the seismic behavior of external rc beam-column joints through experimental tests and numerical simulations. Engineering Structures, 52, 207-219. http://dx.doi.org/10.1016/j.engstruct.2013.02.023

Najafgholipour, M.A., Dehghan, S.M., Dooshabi, A., \& Niroomandi, A. (2017). Finite element analysis of reinforced concrete beam-column connections with governing joint shear failure mode. Latin American Journal of Solids and Structures, 14 (7), 1200-1225. https://doi.org/10.1590/167978253682

Paulay, T. (1971). Coupling beams of reinforced concrete shear walls. Journal of the Structural Division, Proceedings ASCE, 97, $843-861$.

Park, Y-J, \& Ang, A.H-S. (1985). Mechanistic seismic damage model for reinforced concrete. Journal of Structural Engineering, 111 (4), $722-739$. https://doi.org/10.1061/(ASCE)0733-9445(1985)111:4(722)

Ruiz, M. F., \& Muttoni, A. (2007). On the development of suitable stress fields for structural concrete. ACI Structural Journal, 104 (04), $495-502$.

Souza, R. A., Kuchma, D. A., Park, J., \& Bittencourt, T. N. (2007). Non-linear finite element analysis of four-pile caps supporting columns subjected to generic loading. Computers and Concrete, 4, 363-376. http://dx.doi.org/10.12989/cac.2007.4.5.363

Souza, R. A., \& Breña, S. (2016). Behavior predictions of deep beams with short straight bar anchorages using strut-and-tie models and nonlinear analysis. Revista IBRACON de Estruturas e Materiais, 9, 710-721. https://doi.org/10.1590/S1983-41952016000500004 